\title{
Using Structural Measures to Reduce Flood Losses in a Future Extreme Weather Event
}

\author{
Hsiao-Ping Wei ${ }^{1, *}$, Hsin-Chi Li ${ }^{1}$, Keh-Chia Yeh ${ }^{2}$, Jun-Jih Liou ${ }^{1}$, Yung-Ming Chen ${ }^{1}$, and Hsuan-Ju Lin ${ }^{1}$ \\ ${ }^{1}$ National Science and Technology Center for Disaster Reduction, New Taipei City, Taiwan, R.O.C. \\ ${ }^{2}$ Department of Civil Engineering, National Chiao Tung University, Hsinchu, Taiwan, R.O.C.
}

Received 30 July 2015, revised 20 July 2016, accepted 14 July 2016

\begin{abstract}
Climate change is a real threat that brings heavier and more frequent extreme weather events. Many researchers have found that climate change will increase the risk of flooding around the world. The SOBEK inundation model and Taiwan Typhoon Loss Assessment System (TLAS) are used in this study to see if embankment and flood storage control measures can mitigate the impact (loss) of extreme events under climate change. Based on the simulation results, three inundation cases are simulated starting about $18 \mathrm{hr}$ after the embankment is breached. When embankment and detention pond measures are not in place (Case A), the average flood depth in the catchment area caused by the TOP event is roughly $1.45 \mathrm{~m}$. When adaptation measures such as [Case B raising embankments (Case B) and] are in place, the flood depth decreased by 39 and 33\%, respectively. TLAS was used to evaluate the potential losses associated with the three cases (Case A, B, and C). When we add flood-control measures, the total loss reduced by adaptation measures for future extreme events in the Zhengwen River basin was NT \$7 billion. This study provides applicable coping strategies for future extreme precipitation events that will effectively reduce the impact of extreme storm events.
\end{abstract}

Key words: Climate change, Flood control measures, Flood disaster, SOBEK, TLAS

Citation: Wei, H. P., H. C. Li, K. C. Yeh, J. J. Liou, Y. M. Chen, and H. J. Lin, 2016: Using structural measures to reduce flood losses in a future extreme weather event. Terr. Atmos. Ocean. Sci., 27, 757-767, doi: 10.3319/TAO.2016.07.14.02

\section{INTRODUCTION}

Climate change is bringing severe impact to many regions around the world. According to climate projections, when the global temperature increases by $1^{\circ} \mathrm{C}$, precipitation will increase by $1-2 \%$ and atmospheric water-vapour will increase by $6-7 \%$. Rainfall has become even more concentrated in many regions.

Scientists have recently discovered that the frequency of extreme hydrological events will increase under the influence of global warming and climate change. Taiwan is located in the subtropics and impacted by a variety of natural disasters every year including typhoons, torrential rain, droughts, cold snaps, and earthquakes. The Taiwan Climate Change Projection and Information Platform (TCCIP 2010) report showed statistics for the frequency of heavy precipitation typhoons in Taiwan in 1970 - 2009, in which heavy precipitation typhoons occurred roughly once every 2 years

\footnotetext{
* Corresponding author

E-mail:weihp@ncdr.nat.gov.tw
}

before 2000. Heavy rainfall typhoon events have occurred at least once a year since 2000. Typically, the average asset loss directly caused by severe weather each year in Taiwan is about NT $\$ 15$ billion, $85 \%$ of which is related to typhoons. Typhoons bring strong winds and torrential rains that can directly cause many severe disasters, e.g., flash floods, flooding of coastal and low-lying areas and damage to houses, roads, and bridges.

The main scientific tool used for long-term climate simulations is the general circulation model (GCM) (Green et al. 2011). The purpose of the GCM is to project global climate characteristics and trends. Hence, GCM projections (rainfall, temperature, humidity, etc.) are unable to provide adequate, effective information for flooding simulation at the local scale. Scientists have developed various downscaling methods in recent years to increase the spatial resolution, providing more information for correcting the error margin from GCM simulations, as well as presenting the influence of topographic distribution in local areas (Dominguez et al. 2012). 
With such downscaled projection datasets, it is possible to simulate the water level of rivers and 2D flooding depth using proper simulation models. However, less attention has been focused on to what extent flood control measures mitigate the flooding effect with a quantitative value in terms of economic loss. Johnson and Davis (1975) illustrated the computer program HEC-5C capability to analyse structural combinations (such as site elevation using fill or stilts and site protection using dikes or flood walls) and non-structural (such as evacuation/relocation and land use regulation) flood control measures. Ghanbarpour et al. (2008) used the HEC-HMS to model the watershed response to any changes from structural (slope terracing, retarded dam construction, pitting, and furrowing) and non-structural (land use changes) flood control measures and synchronized hydrograph analysis. Kuntiyawichai et al. (2011) integrated hydrological Soil and Water Assessment Tool (SWAT) and 1D/2D SOBEK hydraulic model to evaluate the effectiveness of two structural measures including natural flood storage and green river channel.

Extreme storm events frequently result in socioeconomic impacts and the loss of human life. The flooding has become more severe and more frequent in the last decade, according to the statistical analysis for 1970 - 2009 disasters from heavy rainstorms (NCDR 2010; Hsu et al. 2011). For example, Typhoon Morakot (August 2009) devastated Taiwan and caused over 700 deaths. According to the investigation and statistical data provided by Taiwan's Morakot Post-Disaster Reconstruction Council, the total economic loss from Typhoon Morakot was approximately NT\$6451 million in Taiwan.

The hazard type refers to the natural hazard characteristics, e.g., the flow depth and duration of a flood. Exposure relates to the inventory that suffers a potential loss. If hazard loss is concerned with damage to household assets, the household inventory is used. Vulnerability refers to "the characteristics of a person or a group in terms of their capacity to anticipate, cope with, resist, and recover from the impact of a natural or man-made disaster-noting that vulnerability is made up of many political-institutional, economic, and socio-cultural factors" (Schneiderbauer and Ehrlich 2004). Vulnerability factors are traditionally physical factors, e.g., the anti-shaking ability of buildings, but the factors related to humans are absent (Messner and Meyer 2006).

Even fewer studies have built a flood loss model that includes both exposure and vulnerability variables. Wang et al. (2002a, b) analysed the total flood loss data for 93 typhooninduced floods and built a Taiwan flood damage model. Variables in the model include average total precipitation, population density, per capita income, and wind speed near the center of the typhoon. Li et al. (2008) and Li and Yang (2010) divided residential losses into human resources loss and property loss (e.g., 4 housing structure loss, furniture and household appliance loss, transportation vehicle loss, and oth- er losses), collected data from various types of losses using questionnaire surveys and established a residential disaster loss model. Variables in the model include flood depth, house possessions, household members, flood duration, apartment mansion, residential years, and income. Since the flood loss model includes hazards, exposure, and vulnerability characteristics as variables, the user can further describe risks. To understand the possible changes brought by future climate scenarios to the Zhengwen River basin, this study evaluates to what extent the flooding control measures could mitigate the impact of flood disaster and reduce potential losses.

\section{METHODOLOGY}

\subsection{Overall Conceptual Framework}

This study collected geomorphic and hydrological data from the study area as the inputs of inundation model. Flood control measures such as raising embankments and building a detention pond are added to the inundation model for simulation. Finally, this study evaluates the benefit of these measures for mitigating the impact of flood disaster. This paper is organized as shown in Fig. 1.

\subsection{Flood Simulation}

This study uses the SOBEK model, developed by WL Delft Hydraulics (WL Delft Hydraulics 2006), for flood simulation. SOBEK adopts an integrated approach for river hydraulics and hydrological processes, regional drainage, and urban drainage systems.

This study uses the SOBEK channel flow (CF) module along with the rainfall runoff (RR) module for discharge and water level simulation in river channel. The estimated rainfall runoff volume is calculated as lateral inflow (node) that converges in the main stream when calculating unsteady river channel flow. In the $2 \mathrm{D}$ inundation model, the river channel boundary conditions are the discharge and water level from the river channel hydraulic simulation. The downstream boundary condition is the sea level generated from the coastal hydrodynamic model (full name of FV$\mathrm{COM})$. Overland flow from rainfall in the region is used for calculations for areas beyond the river channel. The flooding situation (position, area, depth) is simulated at $40 \mathrm{~m} \mathrm{spa-}$ tial resolution and $1 \mathrm{hr}$ temporal resolution.

\subsubsection{RR Module}

The rainfall-runoff scheme uses the Sacramento rainfall runoff concept (Burnash et al. 1973). There are four flow component sources including direct runoff, surface runoff, interflow, and base flow in the Sacramento model. Unit Hydrograph is used to transform the runoff from direct runoff, the surface runoff, and the interflow into a discharge hydrograph at a location on the main channel system. 


\subsubsection{CF Module}

River channel simulations include the establishment of relevant structures such as bridges, reservoirs, river-crossing structures (e.g., weirs, culverts, orifices, and pump stations). The water flow is completed by solving the complete De Saint Venant equations. The following equations are solved for one-dimensional flow:

$$
\begin{aligned}
& \frac{\partial A_{f}}{\partial t}+\frac{\partial Q}{\partial x}=q l a t \\
& \frac{\partial Q}{\partial t}+\frac{\partial}{\partial x}\left(\frac{Q^{2}}{A_{f}}\right)+g A_{f} \frac{\partial h}{\partial x}+\frac{g Q|Q|}{C^{2} R A_{f}}-w_{f} \frac{\tau_{\text {wind }}}{\rho_{w}}=0
\end{aligned}
$$

where, $Q$ : discharge $\left(\mathrm{m}^{3} \mathrm{~s}^{-1}\right)$; $h$ : water depth $(\mathrm{m}) ; R$ : hydraulic radius $(\mathrm{m})$; qlat: lateral discharge per unit length $\left(\mathrm{m}^{2} \mathrm{~s}^{-1}\right)$; $A_{f}$ : wetted area $\left(\mathrm{m}^{2}\right) ; w_{f}$ : flow width $(\mathrm{m}) ; \tau_{\text {wind }}$ : wind shear stress $\left(\mathrm{N}=\mathrm{m}^{2}\right) ; \rho_{w}$ : density of water $\left(\mathrm{kg} \mathrm{m}^{-3}\right) . ; t$ : time $(\mathrm{s}) ; x$ : distance $(\mathrm{m}) ; g$ : acceleration due to gravity $\left(\mathrm{m} \mathrm{s}^{-2}\right)(\approx 9.81)$.

\subsubsection{Overland Flow Module}

The overland flood model simulates and subsequently determines the boundary conditions in a river channel based on the flow and water level results from the 1D simulation, although calculations for conditions outside river channels require regional precipitation and land surface overland flow data. The following equations are solved for overland flow:

$$
\begin{aligned}
& \frac{\partial h}{\partial t}+\frac{\partial(u d)}{\partial x}+\frac{\partial(v d)}{\partial x}=0 \\
& \frac{\partial u}{\partial t}+u \frac{\partial u}{\partial x}+v \frac{\partial u}{\partial x}+g \frac{\partial h}{\partial x}+g \frac{u|V|}{C^{2} d}+a u|u|=0 \\
& \frac{\partial v}{\partial t}+u \frac{\partial v}{\partial x}+v \frac{\partial v}{\partial y}+g \frac{\partial h}{\partial y}+g \frac{v|V|}{C^{2} d}+a v|v|=0
\end{aligned}
$$

where, $x: \mathrm{x}$ direction spatial coordinate $(\mathrm{m}) ; y: \mathrm{y}$ direction spatial coordinate $(\mathrm{m}) ; u$ : velocity in $\mathrm{x}$-direction $\left(\mathrm{m} \mathrm{s}^{-1}\right) ; v$ : velocity in y-direction $\left(\mathrm{m} \mathrm{s}^{-1}\right)$; $d$ : depth below plane of reference $(\mathrm{m}) ; V$ : velocity magnitude $\left(=\sqrt{u^{2}+v^{2}}\right)\left(\mathrm{m} \mathrm{s}^{-1}\right) ; a$ : wall friction coefficient $\left(1 \mathrm{~m}^{-1}\right) ; C$ : Chezy coefficient $\left(\mathrm{m}^{1 / 2} \mathrm{~s}^{-1}\right)$.

\subsection{Flood Loss Assessment}

The Taiwan Typhoon Loss Assessment System (TLAS) established by the National Science and Technology Center for Disaster Reduction (NCDR) was used to evaluate the potential losses associated with extreme events. The property loss calculation includes 27 types of land use modules, such as agriculture, forestry, fishery, and animal husbandry loss; industrial and commercial service loss; public building loss; and traffic and hydraulic facilities loss. Variables in the model include flood depth, household possessions, household members, flood duration, apartment mansion, residential years, and income (Li and Yang 2010).

\subsection{Criteria of Comparing the Models}

In order to validate the simulation model, comparisons were made between the simulated and observed water level values and three statistical indices were utilized. These indices are the coefficient of efficiency (CE), error of peak water level $\left(\mathrm{EL}_{\mathrm{P}}\right)$, and error of the time for peak $\left(\mathrm{E}_{\mathrm{TP}}\right)$ :

(1) Coefficient of efficiency, CE

$\mathrm{CE}=1-\frac{\sum_{\mathrm{i}=1}^{\mathrm{n}}\left(\mathrm{L}_{\mathrm{obs}}-\mathrm{L}_{\mathrm{est}}\right)^{2}}{\sum_{\mathrm{i}=1}^{\mathrm{n}}\left(\mathrm{L}_{\mathrm{obs}}-\overline{\mathrm{L}}_{\mathrm{obs}}\right)^{2}}$

(2) Error of peak discharge, EL $L_{P}$

$\mathrm{EL}_{\mathrm{P}}=\frac{\mathrm{L}_{\text {pest }}-\mathrm{L}_{\text {pobs }}}{\mathrm{L}_{\text {pobs }}}$

(3) Error of the time for peak, $E_{T P}$

$\mathrm{E}_{\mathrm{TP}}=\mathrm{T}_{\text {pest }}-\mathrm{T}_{\text {pobs }}$

Where, $\mathrm{L}_{\text {est }}$ denotes the estimating flood discharge (cms); $\mathrm{L}_{\text {obs }}$ represents the observed flood discharge (cms); and $\overline{\mathrm{L}}_{\mathrm{obs}}$ is the mean value of the observed flood discharge $(\mathrm{cms}) ; \mathrm{L}_{\text {pest }}$ and $\mathrm{L}_{\mathrm{pobs}}$ are the peak water level of flood of observation and estimation, respectively; $\mathrm{T}_{\text {pest }}$ and $\mathrm{T}_{\text {pobs }}$ denote the time to peak discharge of estimation and observation, respectively.

\section{CASE ANALYSIS}

\subsection{Study Area}

The Zhengwen River basin is located in the southwest part of Taiwan. The Zhengwen River stretches $138.5 \mathrm{~km}$ long, its basin covers an area roughly $1176.7 \mathrm{~km}^{2}$. The mean annual precipitation and air temperature are approximately $2700 \mathrm{~mm}$ and $19^{\circ} \mathrm{C}$, respectively (Tung 2001). The main Zhengwen River stream contains abundant hydraulic resources including the Zhengwen Reservoir, Taiwan's largest reservoir, Nanhua Reservoir, and Wushantou Reservoir. The Zhengwen Reservoir is located in its basin, which also has the Nanhua Reservoir and Wushantou Reservoir located in this basin (Fig. 2).

\subsection{Geomorphic and Hydrological Data}




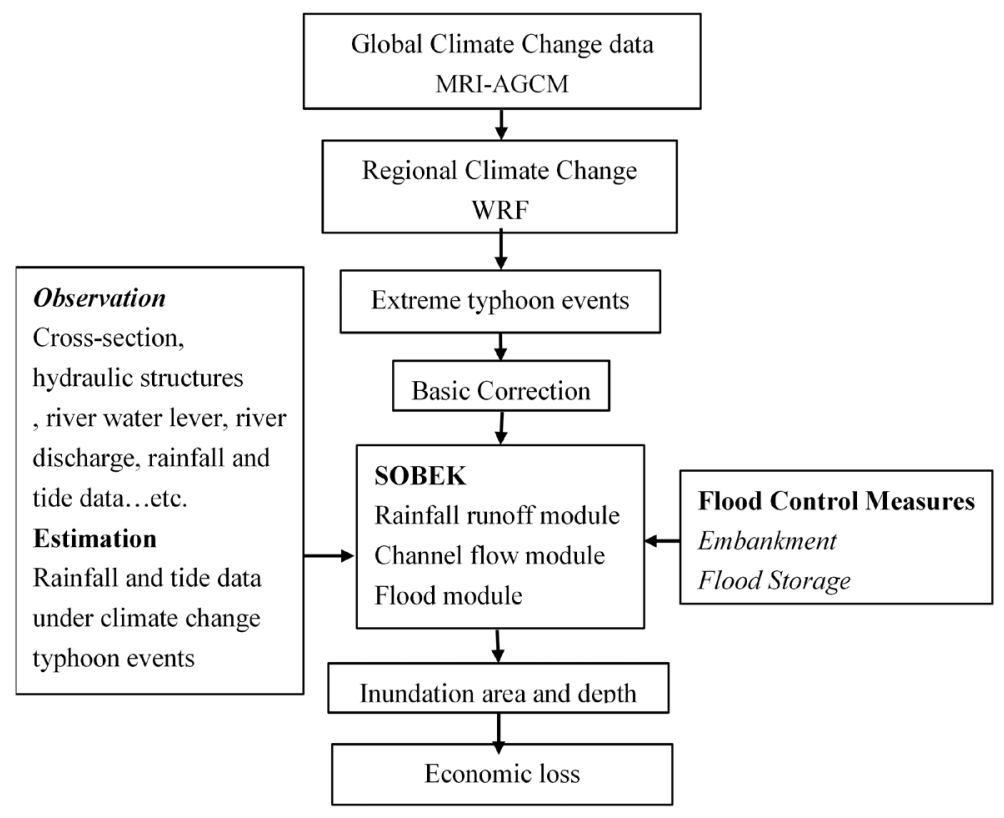

Fig. 1. Research framework.
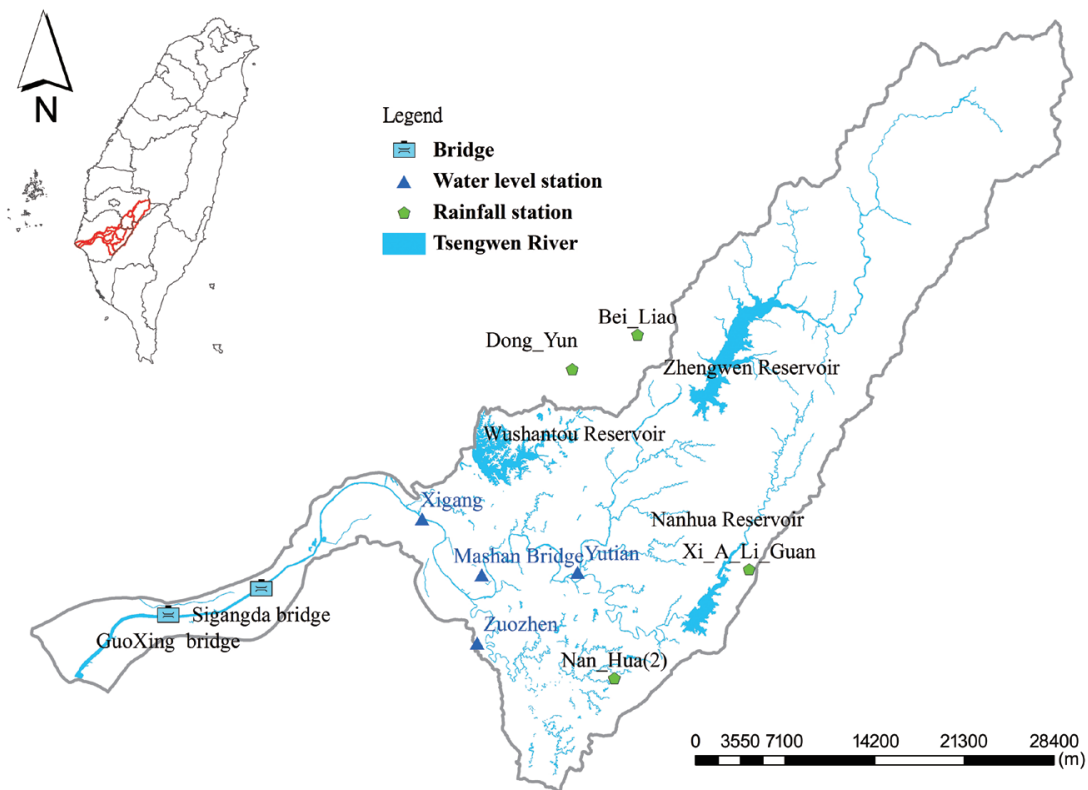

Fig. 2. Map of the Zhengwen River basin in Taiwan.

When simulating the flow rate and water depth at the flooded area it is necessary to first gather geomorphic and hydrological data, including channel cross section, hydraulic structures, future climate extreme typhoon rainfall, land use, and water level.

The collected rainfall data includes historical typhoon rainfall observations and dynamic downscaling data from a future climate change scenario. The collected water level data includes gauge station and tidal station data near the estuary and are used as validation data for the simulation results. Sea level data produced using FVCOM is used as the downstream boundary condition in the SOBEK model. Hence, FVCOM is used to project changes in astronomical tide at the estuary in the future climate change scenario (Chen and Liu 2014). The digital elevation model (DEM) and land use are shown in Fig. 3. In the SOBEK, computational profile the catchment is divided into $1347 \times 888$ cells (horizontal and vertical) with a cell size of $40 \mathrm{~m}$.

This study used the climate projection simulated using the high-resolution $(\sim 20-\mathrm{km}$ horizontal resolution) 

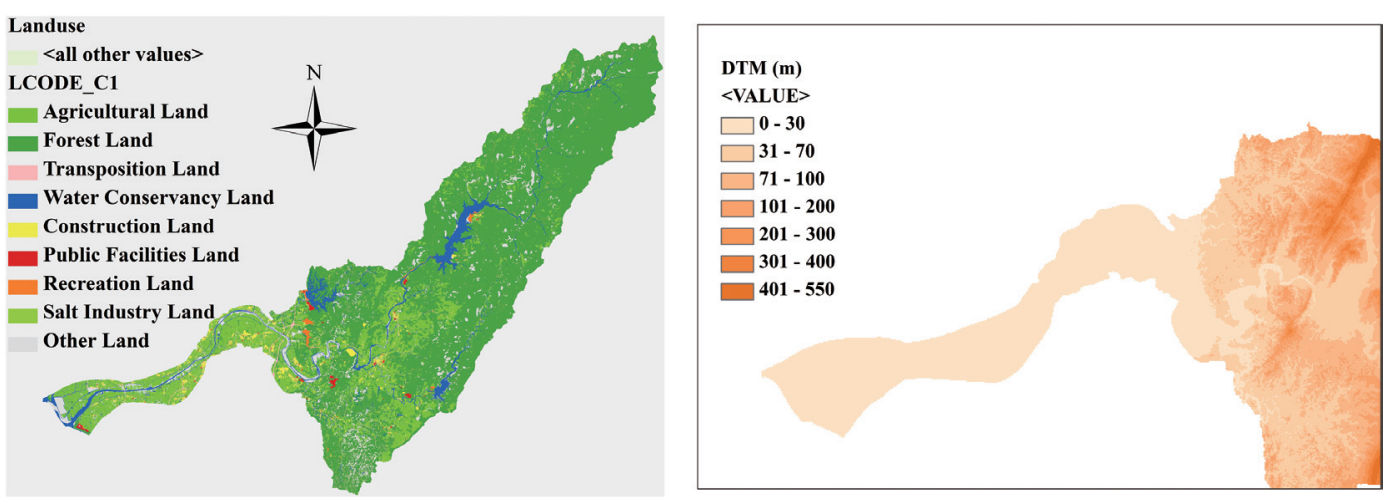

Fig. 3. Surface information of study area (a) Land use map (b) DEM.

atmospheric general circulation model (AGCM) developed by the Meteorological Research Institute (MRI) under the Japan Meteorological Agency (Mizuta et al. 2012) as the initial and boundary conditions to drive a regional model. The weather research and forecasting (WRF) model developed by the National Center for Atmospheric Research, used for conducting dynamic downscaling, produced the dataset termed as MRI-WRF used in this study. The MRI-AGCM, Japan, was developed based on the numerical model originally used for the operational short- and medium-range forecast, and were used by Kitoh et al. (2009) to simulate climate projection with $20-\mathrm{km}$ horizontal resolution for three time segments: late $20^{\text {th }}$ century (baseline, 1979 - 2003), early $21^{\text {st }}$ century (2015 - 2039), and late $21^{\text {st }}$ century (2075 - 2099). Fita et al. (2010) modified the WRF as the CLWRF (Climate WRF), which was adopted in this study to conduct dynamic downscaling of 5-km horizontal resolution.

The selected typhoon events with the highest $24 \mathrm{hr}$ rainfall at the Zhengwen catchment area from baseline (1979 - 2003), the early $21^{\text {st }}$ century (2015 - 2039), and late $21^{\text {st }}$ century (2075 - 2099) generated by the WRF were used to simulate the single most severe future urban flooding event. For the three projection periods, the TOP event at the late $21^{\text {st }}$ century had the most intensive rainfall. However, the bias in the MRI-WRF should be corrected. For details about the bias correction of this dataset please refer to $\mathrm{Su}$ et al. (2016) in this special issue. Su et al. (2016) applied the quantile mapping method to correct the bias and the corrected TOP typhoon event is termed as TOP_BC hereafter. The hourly rainfall of the TOP_BC event is used as the input data for the SOBEK model. The highest tide at the downstream boundary is projected by the FVCOM model, as shown in Fig. 4.

Since MRI-WRF is a grid-based dataset, this study collected rainfall records from WRF grids, which nearby to the four Water Resources Agency's rainfall stations within the study area (Fig. 2).

Typhoon Morakot (2009) brought the highest recorded rainfall in southern Taiwan and is selected as a benchmark event for this analysis. The rainfall records from Typhoon Morakot (2009) and TOP_BC typhoon event in the late $21^{\text {st }}$ century at the four rainfall gauges were used as the flooding simulation model input. The rainfall hyetograph and statistics comparison between Typhoon Morakot and TOP_BC typhoon event in the late $21^{\text {st }}$ century are shown in Fig. 5. For both typhoons, the $48 \mathrm{hr}$ maximum accumulated rainfalls are over $1000 \mathrm{~mm}$ and the highest intensity rainfall was over $60 \mathrm{~mm}$ per hour. Furthermore, the 1, 3, and $6 \mathrm{hr}$ accumulated rainfalls of the TOP_BC typhoon event are higher than that for Typhoon Morakot (Fig. 5). According to the Central Weather Bureau, these two typhoon events (Morakot and TOP_BC in the late $21^{\text {st }}$ century) are categorized as an "extreme torrential rain" with definition of its $24 \mathrm{hr}$ accumulated rainfall exceeding $350 \mathrm{~mm}$.

\subsection{Model Verification}

The SOBEK model requires verification against the observed historical records to ensure the performance of the simulation results. The model was validated using the Fanapi and Morakot typhoon events (Fig. 6). The results showed that the model is capable of reproducing the observed water levels at the Xinzhong water level station. This can also be observed from the three statistical indices (Table 1). The $\mathrm{CE}, \mathrm{EL}_{\mathrm{P}}$, and $\mathrm{E}_{\mathrm{TP}}$ values are $0.81,3 \mathrm{hr}$, and -2.2 (or $0.91,1 \mathrm{~h}$, and 5.5) for Typhoons Morakot and Fanapi, respectively.

Typhoon Morakot was used for 2D inundation simulation model verification. The simulated maximum inundation area was compared to that of field investigations (Fig. 7). Figure 7 shows the simulated maximum inundation area matched the field investigation data to a reasonable extent.

\section{COST EFFECTIVENESS EVALUATION FOR ADAPTATION WORKS}

To investigate the effect of engineering counter-measures, three engineering scenarios were considered using the 


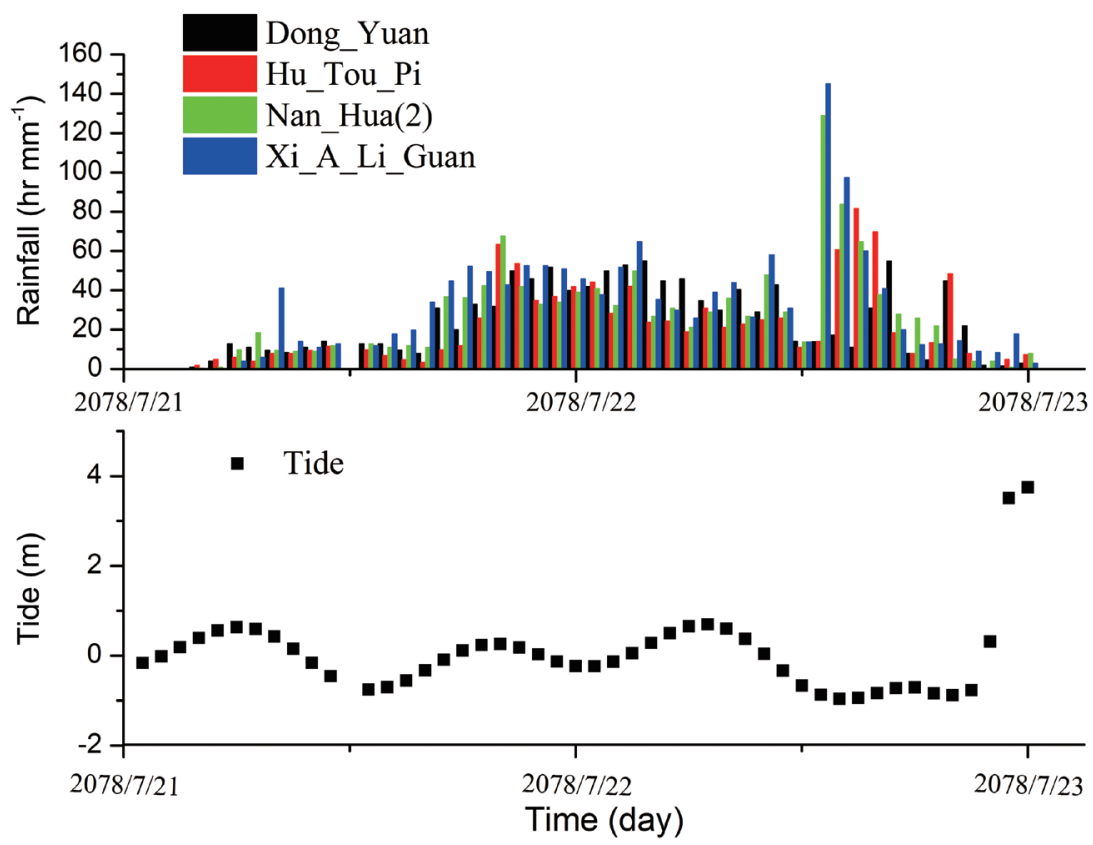

Fig. 4. Rainfall and simulated tidal data for the Typhoon TOP_BC event in the late $21^{\text {st }}$ century.
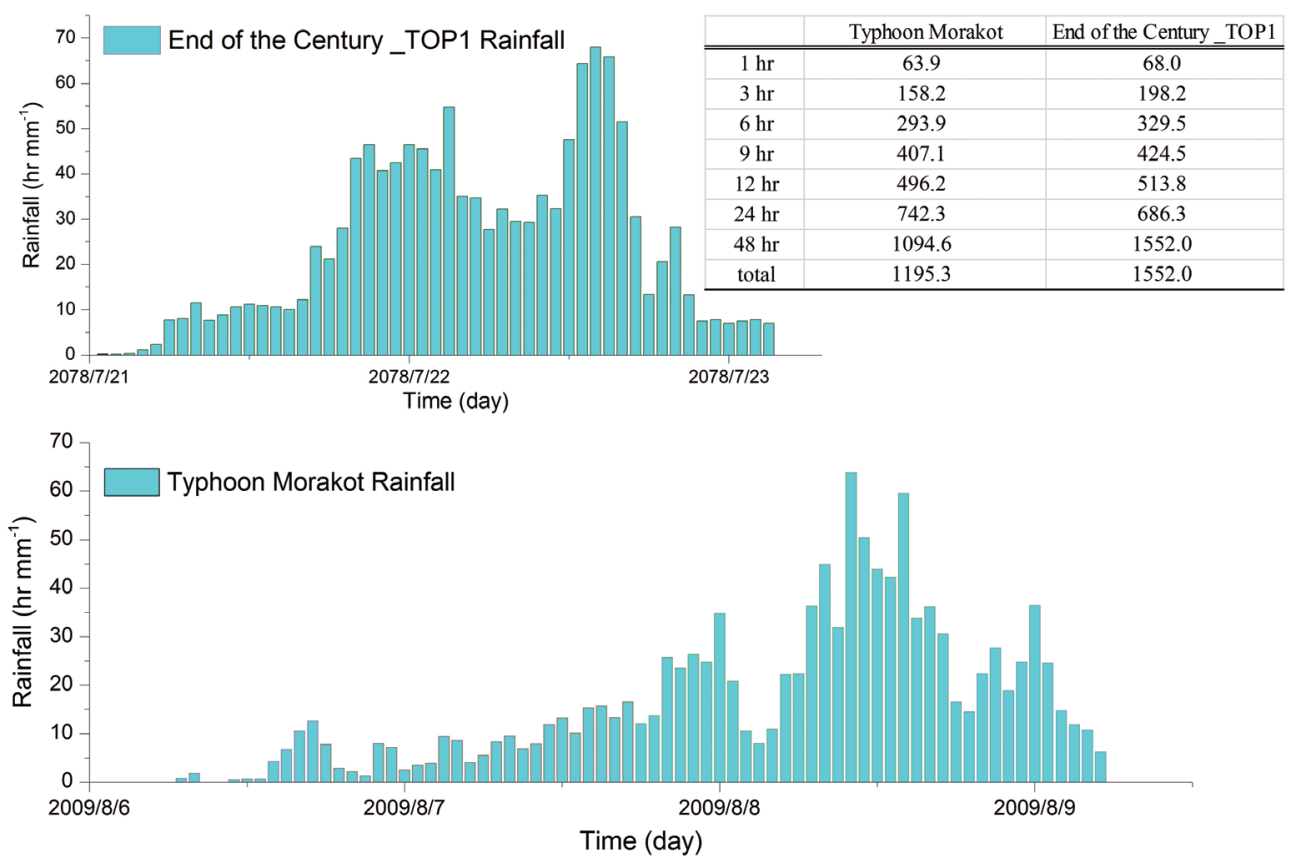

Fig. 5. Comparison between TOP_BC typhoon in the late $21^{\text {st }}$ century and Morakot. 
(a)

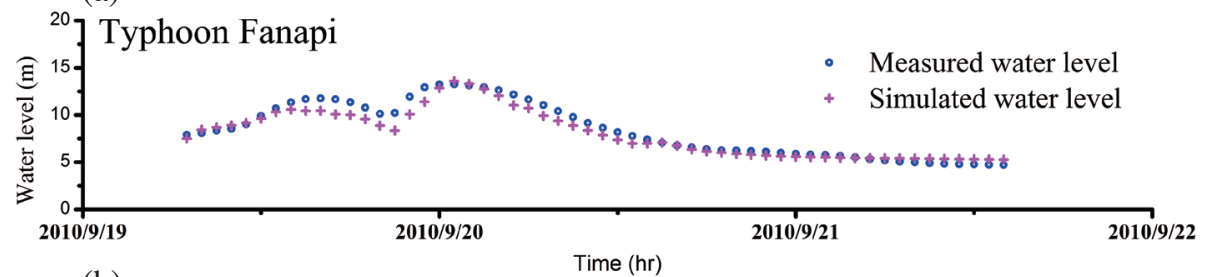

(b)

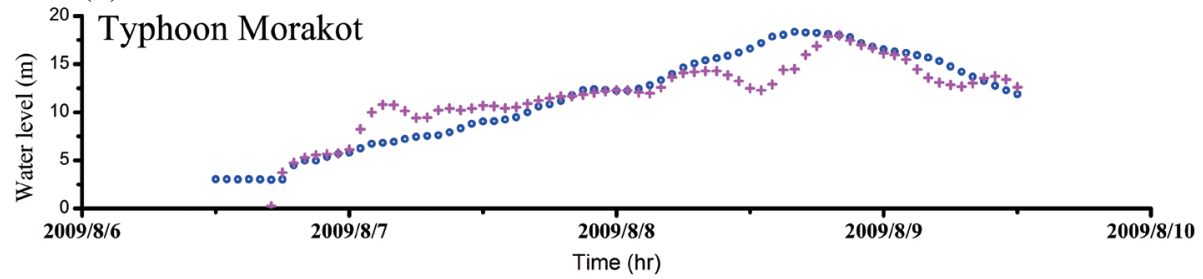

Fig. 6. Comparison of water level between predictions and observation at the Xinzhong water level station for (a) Typhoon Fanapi (2010); (b) Typhoon Morakot (2009).

Table 1. The evaluated indices for Typhoons Fanapi and Morakot at the Xinzhong water level station.

\begin{tabular}{cccc}
\hline Typhoon & $\mathbf{C E}$ & $\mathbf{E}_{\mathbf{T P}}$ & $\mathbf{E L}_{\mathbf{P}}(\boldsymbol{\%})$ \\
\hline Morakot & 0.81 & $3 \mathrm{hr}$ & -2.2 \\
Fanapi & 0.91 & $1 \mathrm{hr}$ & 5.5 \\
\hline
\end{tabular}

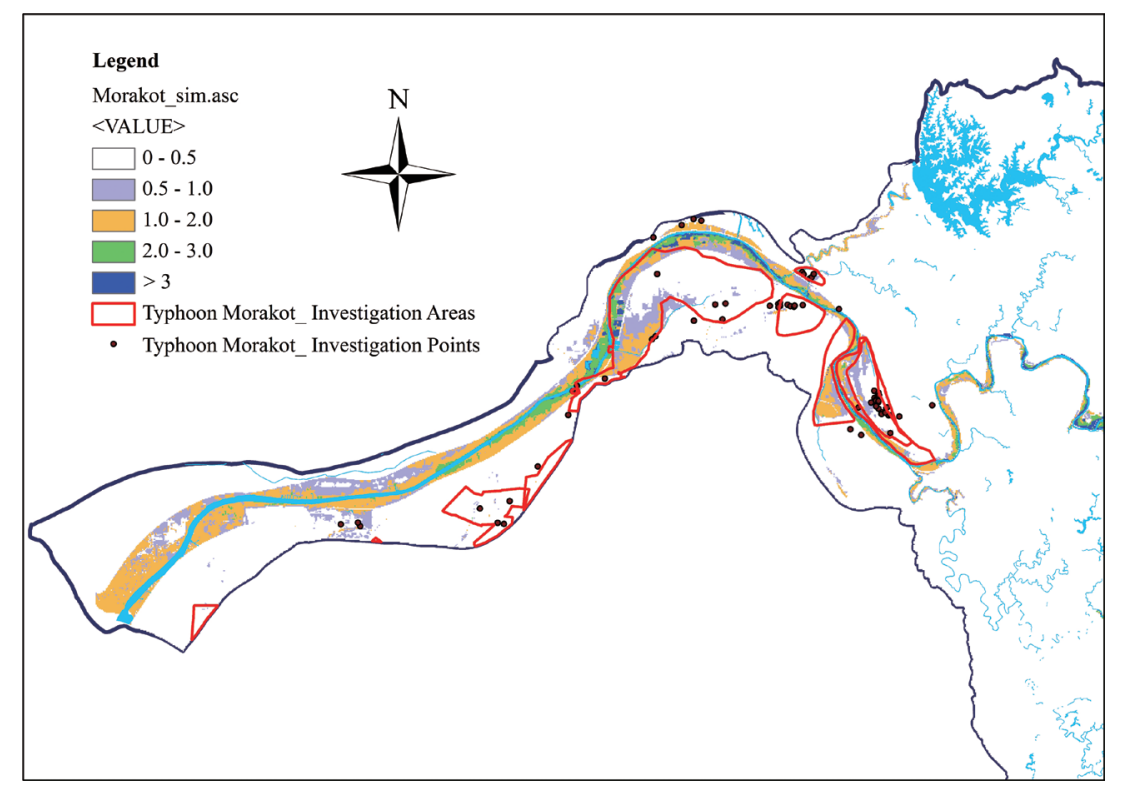

Fig. 7. Comparison of inundation area between the simulation and field investigation for Typhoon Morakot. 
TOP_BC typhoon event in the late $21^{\text {st }}$ century. In the evaluation, we assume that the embankment was breached at the $18^{\text {th }}$ hour in the TOP_BC typhoon event. Case A is the base scenario. It is used as a reference to compare the effects of other measures. In Case B both the right and left embankments are raised by $1 \mathrm{~m}$ with a total length of approximately $20 \mathrm{~km}$ (see the red line in Fig. 8). Case $\mathrm{C}$ involves building a detention pond with a total area of approximately 1500 ha (see the yellow polygon in Fig. 8).

Figure 9 shows that the inundation begins at the $18^{\text {th }}$ hour after the embankment is breached. The inundation area with depth higher than $0.5 \mathrm{~m}$ increased rapidly. In Case A extending the inundation area with depth higher than $0.5 \mathrm{~m}$ stops after about the $41^{\text {st }}$ hour at about $900 \mathrm{~km}^{2}$. Extending the inundation area with a depth higher than $0.5 \mathrm{~m}$ for both Case B and C stops at about $600 \mathrm{~km}^{2}$ after the $41^{\text {st }}$ hour. Figure 9 shows that the inundation area with depth higher than $0.5 \mathrm{~m}$ increased relatively slow for Case B than for the other two cases.

Figure 10 shows Case $\mathrm{B}$ and $\mathrm{C}$ with the maximum flood depth and area distribution diminishing in the middle and lower Zhengwen River catchment. Taking the spatial average of the maximum simulated flood depth, using the TOP_BC typhoon event, in the three cases (Case A, B, and C), the averaged maximum flood depths of $1.45,0.88$, and $0.97 \mathrm{~m}$ in the Zhengwen River basin, respectively. It reveals that with a proper flood control measure, such as raising the embankment in the study area could reduce the flood damage by up to $39 \%$ (Case B).

Figure 11 shows the simulated peak water levels at
GuoXing and Sigangda Bridges for the three cases. From Fig. 11, higher peak water level values could be observed in Case $\mathrm{B}$ and $\mathrm{C}$. The reason for this is that raising the embankment reduces some overbank flow. Cases B and C showed little peak discharge contribution.

The abovementioned results revealed that the flooding control measures are able to significantly reduce the flooding. Furthermore, we discussed the adaptation benefits by conducting economic loss analysis based on the types of land use using the TLAS model. In the TLAS model, the inundation area and depth of Case A (before adaptation) and Case B and C (after adaptation) were used as inputs. This study divided land use into eight categories, namely agriculture, industry, commerce, public facility, transportation facility, hydraulic facility, housing, and tourism (Fig. 12). Figure 12 arranges land use categories by their potential losses, and shows that the transportation facility has the greatest loss, especially at the sides of the river channel, followed by housing loss due to the relatively high population density of Tainan City, which is an urban area. But the Transportation facility and housing land also greatly benefitted, mainly because the flood depth decreased and flood water was retained in the channel (Case B) and detention pond (Case C), greatly reducing the risk of flooding. The transportation network and housing covered the entire area and naturally had great loss during a flooding. When the flooding depth is significantly decreased, the amount of loss is remarkably decreased even though the affected area was still large. For example, a house might encounter considerable loss if the flood depth reaches $1 \mathrm{~m}$ because the furniture and appliances are all immersed

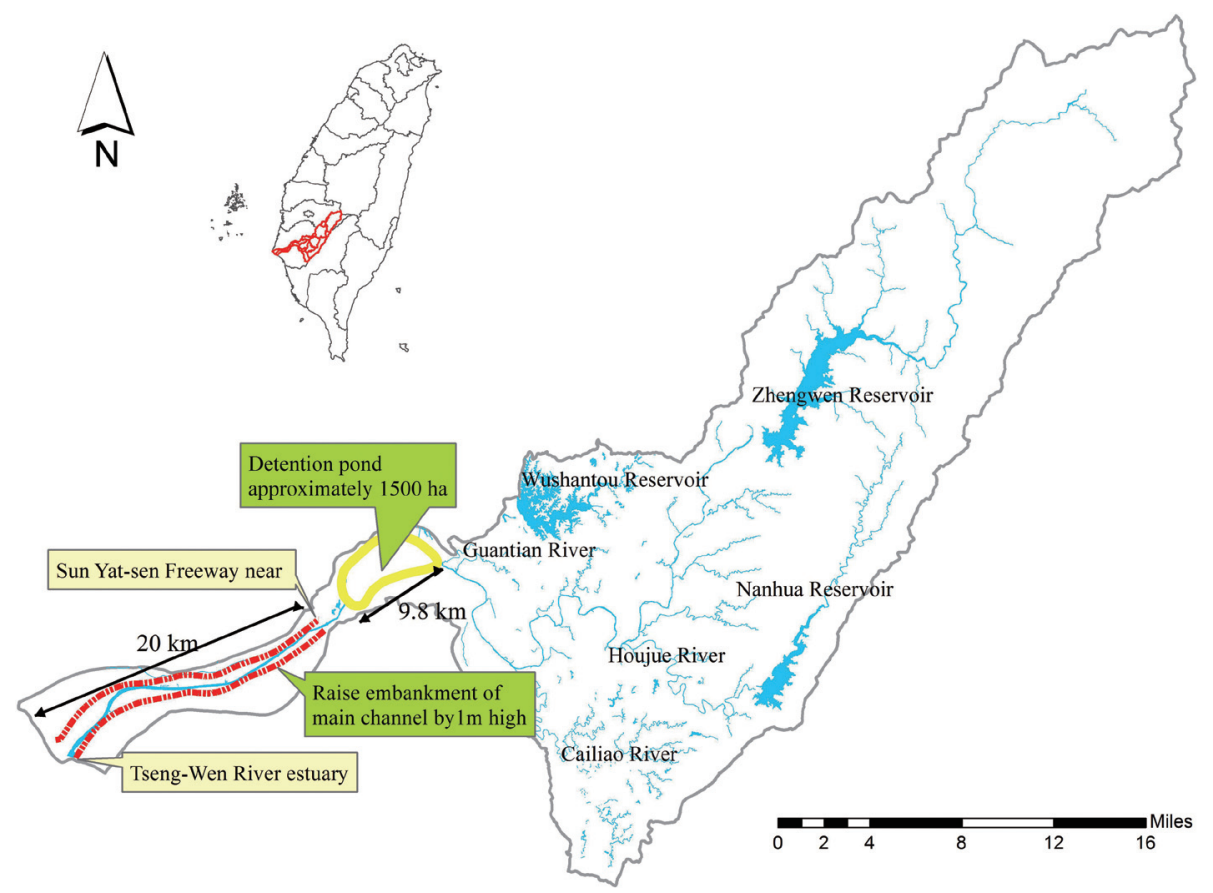

Fig. 8. Illustration of flooding control measures for Case B and C. 


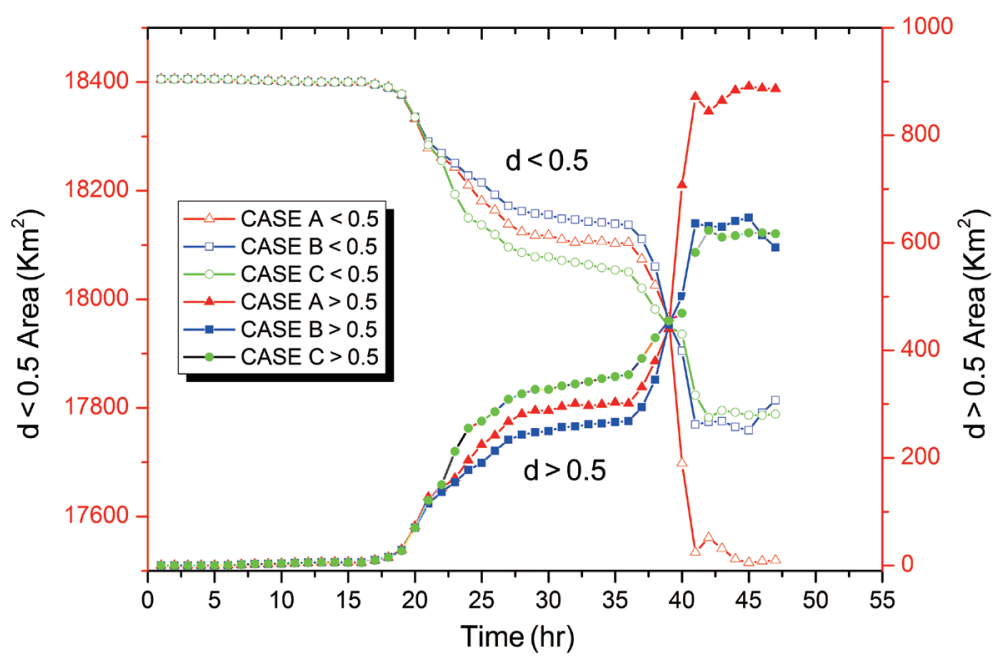

Fig. 9. Variation in inundation area and depth with time.
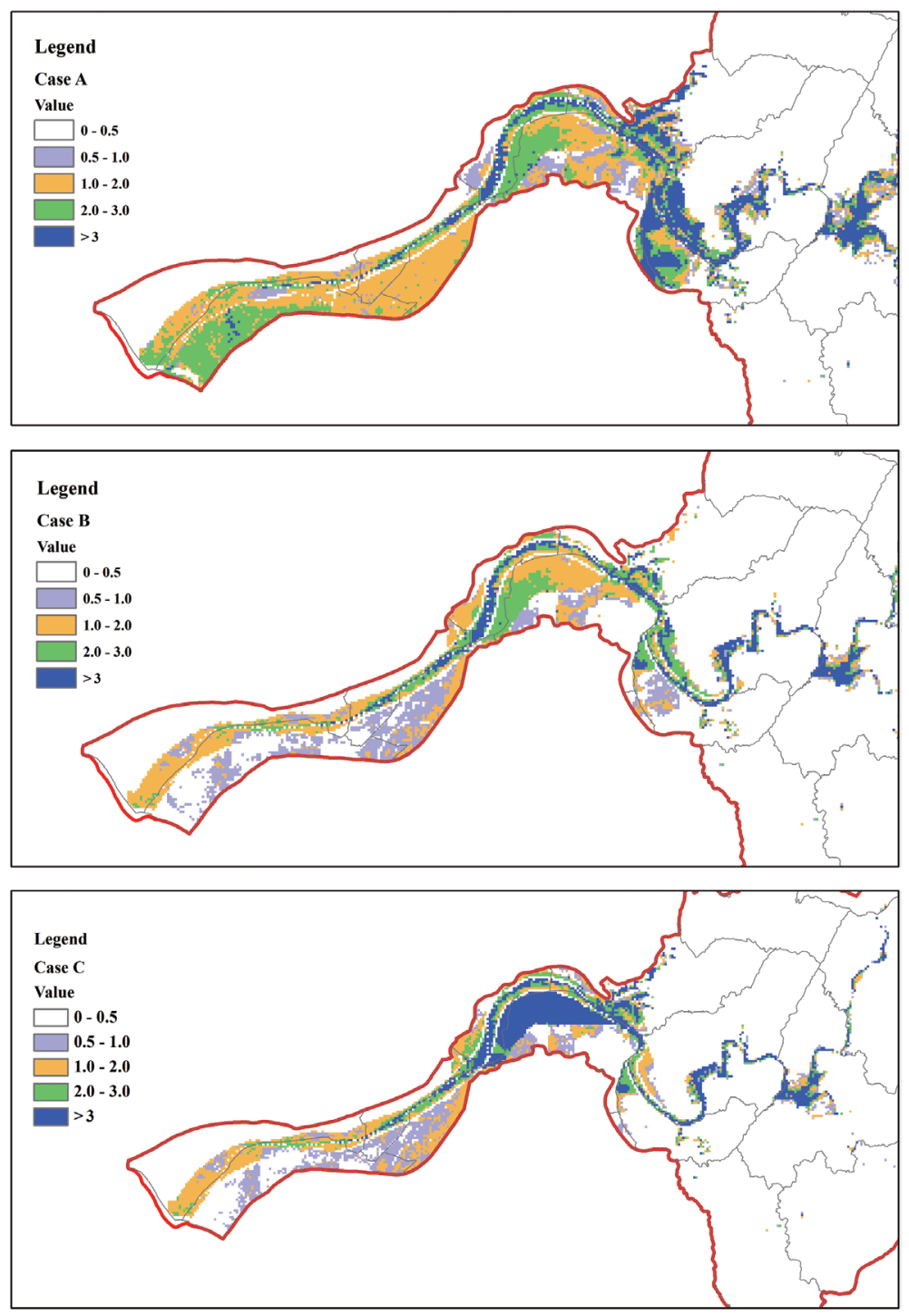

Fig. 10. Maximum flood depth distributions simulated for the three cases using TOP_BC typhoon event under a scenario that the embankment breaks at $18^{\text {th }}$ hour. 

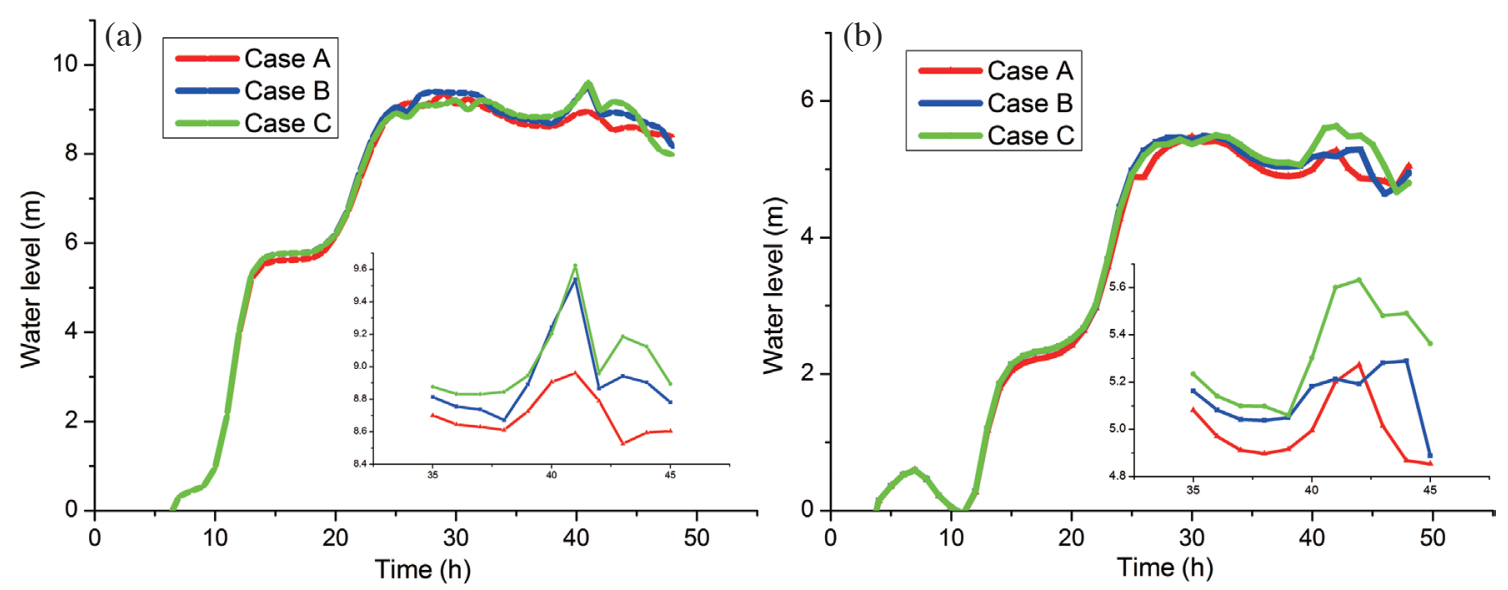

Fig. 11. Simulated peak water levels at the (a) Sigangda and (b) GuoXing bridges.

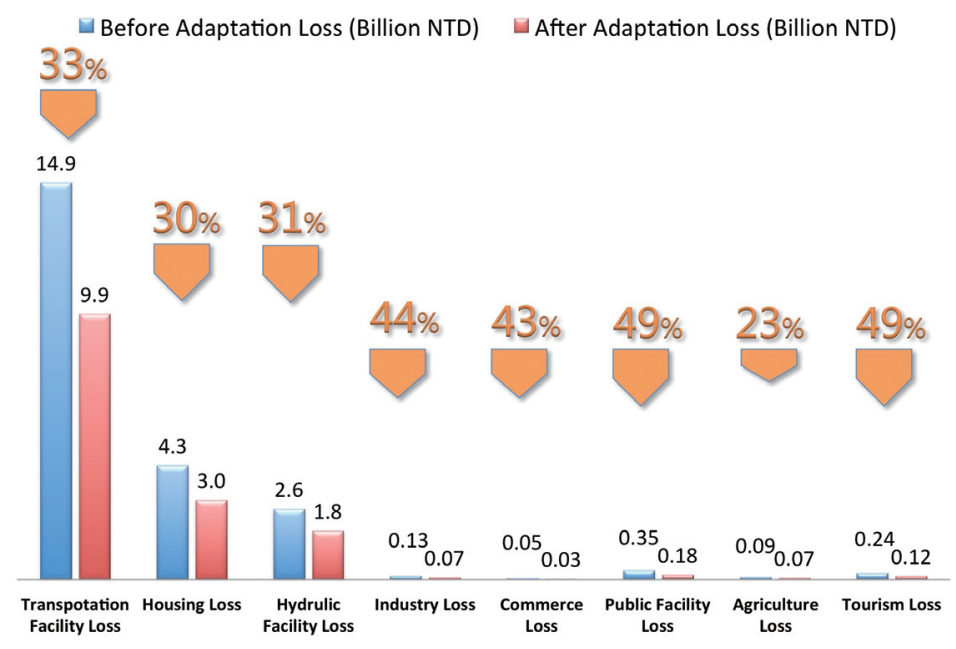

Fig. 12. Loss of each land use category simulated by TLAS.

in water, but if the flood depth decreases to $50 \mathrm{~cm}$, flood water cannot reach the furniture and appliances, which are at a certain height along with the height of the foundation, and the loss is significantly reduced.

Finally, if we add the benefits to all land use categories, the total loss reduced NT $\$ 7$ billion by flooding control measures for future extreme events in Zhengwen River basin.

\section{SUMMARY AND CONCLUSIONS}

Climate change may cause an abnormal increase in intensive rainfall and further increase the risk of river flooding. Hence, it is necessary to conduct a comprehensive review of current river design standards. This study used the Zhengwen River basin as an example. The inundation model was used to determine if flood control measures such as raising the embankment and building a detention pond could mitigate the impact of the most extreme events (TOP_BC) under future climate change scenario.
Based on the simulation results, without additional flooding control measures, the spatially-averaging maximum flood depth in the catchment area caused by the TOP_BC event is roughly $1.45 \mathrm{~m}$. When additional flooding control measures (embankment and detention pond measures) are in place, the average flood depth decreased up to $39 \%$ to $0.88 \mathrm{~m}$. Base on the simulation results for Case B and C, the inundation areas (flood depth greater than $0.5 \mathrm{~m}$ ) are reduced by $300 \mathrm{~km}^{2}$ for the TOP_BC typhoon event in the late $21^{\text {st }}$ century.

TLAS was used to assess the loss in three cases and the results showed that the economic loss could be reduced with additional flood control measures such as raising the embankment and building a detention pond. When $20 \mathrm{~km}$ embankments along the main river channel are raised by $1 \mathrm{~m}$ with a detention pond facility, the total loss would be reduced by NT\$7 billion.

Acknowledgements The authors are grateful for the MRIAGCM3.2S dataset provided by Dr. Akio Kitoh from 
Meteorological Research Institute (MRI) through cooperation between TCCIP project (MOST 103-2621-M-865-001) and SOUSEI project in Japan.

\section{REFERENCES}

Burnash, R. J. C., R. L. Ferral, and R. A. McGuire, 1973: A Generalized Streamflow Simulation System: Conceptual Modeling for Digital Computers, U.S. Department of Commerce, National Weather Service, and State of California, Department of Water Resources, 204 pp.

Chen, W. B. and W. C. Liu, 2014: Modeling flood inundation induced by river flow and storm surges over a river basin. Water, 6, 3182-3199, doi: 10.3390/w6103182. [Link]

Dominguez, F., E. Rivera, D. P. Lettenmaier, and C. L. Castro, 2012: Changes in winter precipitation extremes for the western United States under a warmer climate as simulated by regional climate models. Geophys. Res. Lett., 39, L05803, doi: 10.1029/2011GL050762. [Link]

Fita, L., J. Fernández, and M. García-Díez, 2010: CLWRF: WRF modifications for regional climate simulation under future scenarios. 11th WRF Users' Workshop, Boulder, CO, NCAR: 26. Available at http://www.meteo.unican.es/en/node/72915/.

Ghanbarpour, M. R., M. Teimouri, and S. A. Gholami, 2008: Groundwater contribution to total runoff using baseflow separation: A case study in southwestern Iran. In: Bhattacharya, P., A. L. Ramanathan, A. B. Mukherjee, J. Bundschuh, D. Chandrasekharam, and A. K. Keshari (Eds.), Groundwater for Sustainable Development: Problems, Perspectives and Challenges, Taylor \& Francis Group, London, UK, 13-24, doi: 10.1201/9780203894569.ch2. [Link]

Green, T. R., M. Taniguchi, H. Kooi, J. J. Gurdak, D. M. Allen, K. M. Hiscock, H. Treidel, and A. Aureli, 2011: Beneath the surface of global change: Impacts of climate change on groundwater. J. Hydrol., 405, 532-560, doi: 10.1016/j.jhydrol.2011.05.002. [Link]

Hsu, H. H., C. Chou, Y. Wu, M. M. Lu, C. T. Chen, and Y. M. Chen, 2011: Climate Change in Taiwan: Scientific Report 2011 (Summary), National Science Council, Taipei, Taiwan, R.O.C., 67 pp.

Johnson, W. K. and D. W. Davis, 1975: Analysis of Structural and Nonstructural Flood Control Measures Using Computer Program HEC-5C, US Army Corps of Engineers, Institute for Water Resources, Hydrologic Engineering Center, Davis, California.

Kitoh, A., T. Ose, K. Kurihara, S. Kusunoki, M. Sugi, and KAKUSHIN Team-3 Modeling Group, 2009: Projection of changes in future weather extremes using superhigh-resolution global and regional atmospheric models in the KAKUSHIN Program: Results of preliminary experiments. Hydrol.Res. Lett., 3, 49-53, doi: 10.3178/ hrl.3.49. [Link]

Kuntiyawichai, K., B. Schultz, S. Uhlenbrook, F. X. Suryadi, and A. Van Griensven, 2011: Comparison of flood management options for the Yang River Basin, Thailand. Irrig. Drain., 60, 526-543, doi: 10.1002/ird.596. [Link]

Li, H. C. and H. H. Yang, 2010: A household loss model for debris flow. J. Social Regional Dev., 2, 29-52.

Li, H. C., Y. L. Kuo, D. Shaw, and T. H. Huang, 2008: The household benefits assessment of the flood reduction plan in a Flood-prone Area: A case study of Sinwen, Chiayi, Taiwan. Agric. Resour. Econ., 5, 41-58.

Messner, F. and V. Meyer, 2006: Flood damage, vulnerability and risk perception - Challenges for flood damage research. In: Schanze, J., E. Zeman, and J. Marsalek (Eds.), Flood Risk Management: Hazards, Vulnerability and Mitigation Measures, Springer Netherlands, 149-167, doi: 10.1007/978-1-4020-4598-1_13. [Link]

Mizuta, R., H. Yoshimura, H. Murakami, M. Matsueda, H. Endo, T. Ose, K. Kamiguchi, M. Hosaka, M. Sugi, S. Yukimoto, S. Kusunoki, and A. Kitoh, 2012: Climate simulations using MRI-AGCM3.2 with 20-km grid. J. Meteorol. Soc. Jpn., 90A, 233-258, doi: 10.2151/ jmsj.2012-A12. [Link]

National Science and Technology Center for Disaster Reduction (NCDR), 2010: Introduction of Taiwan Climate Change Projection and Information Platform Project (TCCIP), NCDR report 2010-54, 7 pp.

Schneiderbauer, S. and D. Ehrlich, 2004: Risk, hazard and people's vulnerability to natural hazards: A review of definitions, concepts and data. Technical Report, EUR 21410, Joint Reserach Centre, European Cmomission.

Su, Y. F., C. T. Cheng, J. J. Liou, Y. M. Chen, and A. Kitoh, 2016: Bias correction of MRI-WRF dynamic downscaling datasets. Terr. Atmos. Ocean. Sci., 27, 649657, doi: 10.3319/TAO.2016.07.14.01. [Link]

Taiwan Climate Change Projection and Information Platform (TCCIP), 2010: Taiwan Climate Change Projection and Information Platform (TCCIP) Project Report, NSC 98-2625-M-492-011, Taipei City, Taiwan, R.O.C.

Tung, C., 2001: Climate change impacts on water resources of the Tsengwen creek watershed in Taiwan. J. Am. Water Resour. Assoc., 37, 167-176, doi: 10.1111/ j.1752-1688.2001.tb05483.x. [Link]

Wang, R. Y., S. P. Cheng, and H. Y. Huang, 2002a: Hazard risk and analysis of typhoon damages in urban areas. $J$. Chinese Agric. Eng., 48, 1-16.

Wang, R. Y., S. P. Cheng, and M. D. Su, 2002b: Establishment of Systematic Models for Flood Damage Evaluation (1/2), Water Resources Agency, Ministry of Economic Affairs, Taipei, Taiwan, R.O.C.

WL Delft Hydraulics, 2006: SOBEK Software User's Manual, Delft, the Netherlands. 